\title{
Patients hospitalized for COPD have a high prevalence of modifiable risk factors for exacerbation (EFRAM study)
}

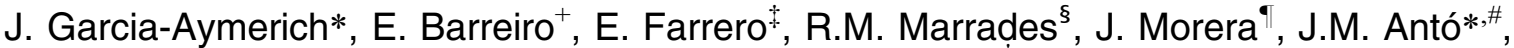 \\ and the EFRAM investigators
}

Patients hospitalized for COPD have a high prevalence of modifiable risk factors for exacerbation (EFRAM study). J. Garcia-Aymerich, E. Barreiro, E. Farrero, R.M. Marrades, J. Morera, J.M. Antó, and the EFRAM investigators. (C) ERS Journals Ltd 2000. ABSTRACT: There is little information available concerning the extent to which chronic obstructive pulmonary disease (COPD) patients are satisfactorily managed, especially, regards factors supposedly related to COPD exacerbation. The present study assessed the prevalence rates of potentially modifiable risk factors of COPD exacerbation in patients hospitalized for this reason.

A systematic sample of one out of two patients admitted for COPD exacerbation, during $1 \mathrm{yr}$, in four tertiary hospitals in the Barcelona area, Spain, was performed. Patients answered a questionnaire and underwent anthropometric measurements, spirometric tests and arterial blood gas sampling. Prevalence rates and $\mathbf{9 5 \%}$ confidence intervals $(95 \% \mathrm{CI})$ for risk factors were obtained, and the generalized estimating equation (GEE) method was used to allow for patients to provide information on different admissions.

The study recruited 353 patients (29 female) with a total of 404 admissions age (mean \pm SD) $69 \pm 9$, median forced expiratory volume in one second (FEV1) $31 \%$ of predicted and mean partial pressure of oxygen $\left(\mathrm{PO}_{2}\right) 63 \pm 13 \mathrm{mmHg}$. Of these, $28 \% \mathrm{had}$ not received an influenza vaccination; a high number $(\mathbf{8 6 \%})$ did not attend rehabilitation programmes; $28 \%$ of patients with $\mathrm{PO}_{2} \leq 55 \mathrm{mmHg}$ were not using long-term oxygen therapy (LTOT); among LTOT users, $18 \%$ used it $<15 \mathrm{~h}$ a day; $43 \%$ of the total failed in some of the essential inhaler manoeuvres; $26 \%$ were current smokers; $21 \%$ of noncurrent smokers were exposed to passive smoking at home; current occupational exposure was low (5\%).

In summary, the authors found a moderate to high prevalence of potentially modifiable risk factors in a large representative sample of patients hospitalized for a chronic obstructive pulmonary disease exacerbation, suggesting unsatisfactory features in their management.

Eur Respir J 2000; 16: 1037-1042.
*Respiratory and Environmental Health Research Unit, IMIM, Barcelona, ${ }^{+}$Dept of Pneumology, Hospital del Mar, Barcelona, "Dept of Pneumology, Ciutat Sanitària i Universitària de Bellvitge, L'Hospitalet de Llobregat, ${ }^{\S}$ Dept of Pneumology, Hospital Clinic i Provincial de Barcelona, Barcelona, "Dept of Pneumology, Hospital Germans Trias i Pujol, Badalona, "Dept of Experimental and Health Sciences, Universitat Pompeu Fabra, Barcelona, Spain.

Correspondence: J.M. Antó, Respiratory and Environmental Health Research Unit, Institut Municipal d'Investigació Mèdica (IMIM) Universität Pompeii Fabro, Doctor Aiguader 80, E-08003-Barcelona, Catalonia, Spain. Fax: 3432213237

Keywords: Chronic obstructive pulmonary disease, exacerbation, prevalence, risk factors

Received: December 281999 Accepted after revision July 282000

This study was supported in part by grants from Agència d'Avaluació de Tecnologia Mèdica (n 5/34/96), and Generalitat de Catalunya-CIRIT 1999SGR 00241, J. Garcia-Aymerich has a fellowship from Instituto de Salud "Carlos III" (n exp. 97/ 4365).
Chronic obstructive pulmonary disease (COPD) is characterized by a chronic slowly progressive limitation of the airflow. As the damage is largely irreversible, the major goals of COPD management are to lessen airflow limitation, prevent and decrease symptoms, prevent and treat medical complications and improve daily living and quality of life [1]. The acute exacerbation of COPD is among the relevant events in the progression of the disease, and its occurrence has been related to the lower survival [2] and decrease in the quality of life [3] of COPD patients. Acute exacerbations are also an important cause of health expenditure, due to hospitalization, outpatient care and drug consumption [1]

Although respiratory infection is assumed to be the main risk factor for the exacerbation of COPD [4], other factors are also involved. Health education of patients, smoking cessation, pulmonary rehabilitation, good nutritional status, and early medical intervention are all considered helpful in preventing exacerbations [5]. Information concerning the extent to which COPD patients are satisfactorily managed with regards these factors, although likely to show strong local variations, is relevant for the formulation of general COPD guidelines. However, the authors were only able to find one descriptive study [6] assessing the prevalence of factors such as medical treatment, long-term oxygen therapy (LTOT), influenza vaccination and pulmonary rehabilitation in patients hospitalized for COPD. This study included a small number of patients $(n=80)$, recruited from one hospital only, and covered a period of no more than 8 weeks. The lack of knowledge about both the aetiological importance of some putative risk factors and the effectiveness of their modification, in terms of reducing COPD admissions, may have favoured an insufficient attention to this issue.

The EFRAM project was aimed at both the assessment of the prevalence of plausible risk factors of COPD exacerbation in a cross-sectional survey of patients hospitalized for this reason, and the identification of risk factors in a case-case design. The present study reports prevalence rates of potentially modifiable risk factors, using a large 
sample of COPD patients admitted for an exacerbation of the disease, over a 1-yr period.

\section{Methods}

\section{Design and subjects}

A cross-sectional study, with systematic sampling of one out of two patients hospitalized or remaining in the emergency room for at least $18 \mathrm{~h}$ for an exacerbation of COPD, in four tertiary national health service hospitals in the Barcelona area over 1 yr (May 1 1997-April 30 1998) was performed.

The COPD diagnosis was obtained from the diagnostic section of the pneumology ward lists. The ward pneumologist's diagnosis was based on the anamnesis (current symptoms and medical history) and, when available, on the results of previous pulmonary function tests, following the European Respiratory Society (ERS) guidelines [1]. On admission, the first diagnosis of all the subjects was the exacerbation of COPD. The exclusion criteria were: 1) mentally unable to answer a questionnaire; 2) severe comorbidity; 3) transtracheal catheter; 4) living outside of the province of Barcelona. During recruitment, the patients excluded were replaced by those of the one in two system who had not been initially included. After the recruitment phase, three admissions were excluded because of a forced expiratory volume in one second $(\mathrm{FEV} 1) /$ forced vital capacity ratio (FVC) $>88 \%, 17$ admissions for positive bronchodilator tests and one admission for a further diagnosis of pulmonary fibrosis. Nonresponders were not replaced and certain information was obtained from their medical records.

The protocol was approved by the Ethics Committees of the participating hospitals, and written informed consent was obtained from all the patients.

\section{Measures}

During hospitalization, patients were asked to complete a long questionnaire and anthropometric measurements were made. At least three months after hospitalization, and during a clinically stable period of COPD, patients performed a spirometric test and provided arterial blood to measure gas tensions. Neither spirometry or blood gases were repeated if the results were already available from the three months prior to hospitalization, during a period of clinical stability.

Information about potentially modifiable risk factors of COPD exacerbation was obtained by an extensive bibliographic search (Medline and The Cochrane Library) for "COPD" and "exacerbation/admission/hospitalization". Certain known risk factors for the exacerbation of COPD were found: no influenza vaccination [7] and high air pollution exposure [8]. In addition, other factors were found, related to the poor progress of the disease, that could be considered potential risk factors for exacerbation: no respiratory rehabilitation [9], underprescription of LTOT and noncompliance with it [10,11], current [12] and passive [13] smoking and occupational exposure [14]. Other potentially relevant factors as suggested by members of the study group were: poor inhaler manoeuvres, no pneumococcal vaccination, consumption of alcohol and sedatives, and no physical activity.

Sociodemographic data, and a list of 11 chronic conditions, were obtained from questions used in health surveys in Barcelona [15]. Socioeconomic status was assigned according to occupation, using an adapted version of the British Registrar General's Social Classes [16]. Dyspnoea before exacerbation was assessed retrospectively with the Borg scale [17]. Factors related to health services were as follows: characteristics and content of visits to the physician monitoring the disease, number of hospitalizations and emergency and doctor's visits during the previous year, current pharmacological treatment, LTOT, influenza and pneumococcal vaccination and pulmonary rehabilitation. For most of these, an ad hoc questionnaire was developed which was piloted for understanding and feasibility. Influenza and pneumococcal vaccinations were self-reported by the patient and taken from the vaccination card, whenever available. Rehabilitation was defined as when the patient reported doing rehabilitation exercises or respiratory gymnastics, including blowing up balloons or balls. Underprescription of LTOT was defined as when the patient had $\mathrm{PO}_{2}<55 \mathrm{mmHg}$ and did not use LTOT. Noncompliance with LTOT was defined as when the patient reported using it $<15 \mathrm{~h}$ a day. Other exposures included: active and passive smoking [18], occupational pollution exposure [18], alcohol consumption [15], sedative consumption and physical exercise. Current smokers were defined as those who had smoked during the month prior to hospitalization. Passive smoking was defined as when "somebody" smoked regularly in the patient's house. Occupational exposure was defined as a positive answer to the question, "Do you work exposed to vapours, gas, dust or fumes?". No physical activity was defined as when the patient did not walk, climb stairs, do any other physical exercise or attend respiratory rehabilitation. Inhaler compliance was measured with inhaler-specific checklists [19], and the three items considered essential for metered dose inhalers (MDI) were: "shaking before use", "inhaling slowly while simultaneously activating the canister" and "inhaling slowly throughout discharge" [19]. Physical examination included weight, height and tricipital skin-fold thickness. The clinical register of the hospital revealed whether or not this was the first time the patient was admitted for COPD.

Spirometry and the bronchodilator test were performed using standard techniques [20]. Reference FEV1 values were obtained from selected volunteers from the Barcelona area [21]. The severity of COPD was staged according to American Thoracic Society guidelines [22], selected $a$ posteriori because ERS cut-off points did not discriminate in the present study sample. Blood gas tensions were measured breathing room air. Cut-off points for $\mathrm{PO}_{2}$ were taken from indications for LTOT administration of COPD guidelines [1, 22].

\section{Statistical analysis}

Sample size estimations suggested that 452 episodes would have to be recruited to obtain prevalence rates of $50 \%$ with a precision of $\pm 5 \%$, accepting an alpha risk of 0.05 for a two-sided test, and anticipating a nonresponses rate of $15 \%$. Bearing in mind the number of COPD 
discharges in the four hospitals in $1996(n \sim 1400)$, systematic sampling of one out of two COPD admissions was decided upon. Patients were allowed to enter the study as many times as they were hospitalized during the study period.

A comparison of responses and nonresponses was made with an unpaired t-test (for quantitative variables of normal distribution), Wilcoxon test (for quantitative variables of non-normal distribution) or Chi-squared (for qualitative variables). In order to allow the patients with more than one admission to provide information on the different admissions, the generalized estimating equation (GEE) method, with an unstructured correlation matrix to allow for within-individual correlation, was used [23]. Moreover, this method provides individual-based proportions. a more interpretable result than episode-based proportions. Proportions and $95 \%$ confidence intervals $(95 \% \mathrm{CI})$ of modifiable known or potential risk factors of exacerbation were calculated from logistic regression estimates, adjusting for sex, age, marital status and level of education. A comparison between categories of variables in the logistic model was carried out with the Wald test. The analysis was performed with Stata, release 5.0 (StataCorp, College Station, TX, USA).

\section{Results}

Table 1, shows the demographic and clinical characteristics of the study sample. A total of 492 eligible episodes were approached, from which 404 (353 patients) accepted to participate. The reasons for nonresponse ( $\mathrm{n}=88$ admissions (78 patients), 18\% of total) were: 79 refusals, two discharges before the interview and seven deaths. Nonresponders (table 1) did not differ in terms of the number of admissions, sex, age, length of hospital stay and percentage of predicted FEV1, from responders, although the proportion that were married was lower and they had less comorbidity. Regarding risk factors, there was no difference in current smoking, alcohol intake or influenza vaccination between responders and nonresponders, but the nonresponders used more LTOT (51\% versus $33 \%, \mathrm{p}=0.004)$. For 63 admissions (61 patients) spirometric data was not available (because the patients had died, dropped out, could not perform the test or were clinically unstable all the time). These patients had less comorbidity $(79 \%$ versus $92 \%, \mathrm{p}=0.004)$ than patients who had performed spirometric tests, but no difference was found in the remaining variables.

Most of the risk factors showed moderate to high prevalence (table 2). The most frequent risk factors were no rehabilitation $(86 \%)$ and failures with the MDI manoeuvre $(43 \%)$. Current occupational exposure $(5 \%)$ and noncompliance with LTOT (18\%) were less common. The frequency of current smokers was lower in females when compared to males $(10 \%$ versus $27 \%, \mathrm{p}=0.038)$. Stratifying age in tertiles ( $<65$ yrs; $65-73$ yrs; $>73$ yrs), the youngest group made less mistakes with inhaler manoeuvres $(32 \%$ versus $48 \%$ and $48 \%, p=0.018)$ and a trend was observed with regards active smoking (40\%, $29 \%$ and $11 \%, \mathrm{p}<0.0005)$. After adjusting for sex and age, the only difference between married and unmarried (single, widowed or divorced) subjects, was in terms of inhaler manoeuvres in married subjects $(37 \%$ of some mistake versus $57 \%, \mathrm{p}=0.002$ ). The same was true for patients with at least primary education with respect to those who had received less than primary education $(32 \%$ versus $51 \%, \mathrm{p}<0.0005)$. No difference was found in the prevalence of risk factors between subjects who belonged to high (I-III) or low (IV-V) socioeconomic status, or between patients hospitalized for the first time for COPD

Table 1. - Characteristics of patients hospitalized by chronic obstructive pulmonary disease (COPD) exacerbation in the Barcelona area during May 1997-April 1998

\begin{tabular}{|c|c|c|c|c|c|}
\hline & \multicolumn{3}{|c|}{ Responders } & \multirow{2}{*}{$\frac{\text { Nonresponders }}{\text { Total }}$} & \multirow{2}{*}{ p-value } \\
\hline & Males & Females & Total & & \\
\hline Subjects n & 324 & 29 & 353 & 78 & \\
\hline \multicolumn{6}{|l|}{ Number of admissions } \\
\hline 1 & $284(88)$ & $26(90)$ & $311(88)$ & $70(90)$ & 0.593 \\
\hline 2 & $34(10)$ & $3(10)$ & $37(10)$ & $6(8)$ & - \\
\hline$>2$ & $6(2)$ & - & $6(2)$ & $2(2)$ & - \\
\hline Males & & & $324(92)$ & $71(91)$ & 0.826 \\
\hline Age yrs & $69 \pm 9$ & $72 \pm 10$ & $69 \pm 9$ & $71 \pm 8$ & 0.067 \\
\hline Married & $250(77)$ & $8(28)$ & $258(73)$ & $42(54)$ & 0.001 \\
\hline Current workers & $22(7)$ & $2(7)$ & $24(7)$ & - & - \\
\hline Less than primary education & $187(58)$ & $20(69)$ & $207(58)$ & - & - \\
\hline Socioeconomic status IV or V & $232(72)$ & $23(79)$ & $255(72)$ & - & - \\
\hline Admissions $\mathrm{n}$ & 372 & 32 & 404 & 88 & \\
\hline Length of hospital stay & $9(6-14)$ & $11(6-19)$ & $9(6-14)$ & $8(5-15)$ & 0.131 \\
\hline At least one coexisting chronic condition ${ }^{+}$ & $331(89)$ & $31(97)$ & $362(90)$ & $60(75)$ & 0.000 \\
\hline Percentage of predicted FEV1 & $30(23-39)$ & $43(33-46)$ & $31(23-41)$ & $31(23-41)$ & 0.920 \\
\hline $\mathrm{PO}_{2} \mathrm{mmHg}$ & $63 \pm 13$ & $60 \pm 14$ & $63 \pm 13$ & - & - \\
\hline Dyspnoea score & $3.7 \pm 2.2$ & $3.2 \pm 2.3$ & $3.7 \pm 2.2$ & - & - \\
\hline Hospitalizations for COPD & $1.9 \pm 2.4$ & $2.1 \pm 3.2$ & $1.9 \pm 2.5$ & - & - \\
\hline Body mass index $\mathrm{kg} \cdot \mathrm{m}^{-2}$ & $25.6 \pm 4.6$ & $30.6 \pm 8.0$ & $26.0 \pm 5.1$ & _- & - \\
\hline
\end{tabular}

Data are presented as $\mathrm{n}(\%)$, mean $\pm \mathrm{SD}$ or median (interquartile range). ${ }^{*}$ : comparison between responders and nonresponders; ${ }^{+}: 8$ missing values in nonresponders; ${ }^{\#}$ : data includes hospitalizations in the last year. $\mathrm{FEV} 1$ : forced expiratory volume in one second; $P \mathrm{O}_{2}$ : partial pressure of oxygen. T-test for age; Wilcoxon test for length of hospital stay and FEV1; and Chi-squared for number of admissions, sex, marital status and coexisting chronic conditions. 
and those with previous admissions for COPD, or between admissions in winter (October-March) and summer (April-September). After adjusting for sex, age, marital status and level of education, current smoking was less frequent in the more severe group of patients (table 2). Apart from that, no other differences were found between the different groups of severity or the group with no spirometric readings. With respect to the prevalence of other potential risk factors of exacerbation, $97 \%$ of individuals had not received pneumococcal vaccination, $16 \%$ reported no physical activity, $32 \%$ and $15 \%$ respectively consumed alcohol and sedatives in the previous month, after adjusting for sex, age, marital status and level of education.

Other information regarding the patient's attitude and the doctor's advice was obtained. Ninety-two per cent of current smokers had at some time tried to stop or cut down. Although $95 \%$ of current smokers had been advised in the past year not to smoke by their principal physician only $36 \%$ reported receiving advice about the best way to stop smoking. With respect to the methods that could be employed, only $17 \%$ received information about nicotine replacement therapy, $13 \%$ about smokers groups and $20 \%$ about specialized services. Only half of the patients reported that their physicians had recommended that they should not be exposed to smoking at home. Of the $28 \%$ of subjects with underprescription of LTOT, 21 subjects $(88 \%)$ had previously been admitted for COPD, and 10 $(42 \%)$ currently smoked. MDI was the most frequently used bronchodilator device in the study sample $(88 \%$ versus $1 \%$ Accuhaler $\AA$ and $12 \%$ Turbohaler $\AA$ ). Although $85 \%$ of subjects reported having been taught inhaler manoeuvres at their first visit to the physician, and $80 \%$ rechecked at each of the following visits, $43 \%$ of them had failed to adequately perform some of the essential MDI manoeuvres, while only $16 \%$ failed to adequately perform some of the essential Turbuhaler $\mathbb{R}$ manoeuvres.

\section{Discussion}

A high prevalence of several modifiable risk factors was found, such as "no rehabilitation" and poor inhaler manoeuvres, in patients hospitalized for COPD exacerbation. Other factors, such as no influenza vaccination, underprescription of LTOT and smoking, showed a moderate level of prevalence, likewise important for their potential harmful effects.

The overall influenza vaccination rate for the group of exacerbated COPD patients was $72 \%$, higher than the $40 \%$ found by Poole et al. [6] in a similar group of patients, it was also similar to the $70 \%$ found in other populationbased studies of chronic respiratory patients [7]. Many guidelines for COPD recommend influenza vaccination, as it protects against hospitalization and death in chronic respiratory patients [7].

The number of patients found to be attending pulmonary rehabilitation programmes was $14 \%$, a level which falls between the 5-8\% found in Switzerland [24] and the 24\% in New Zealand [6]. If the criteria of the COPD guidelines were applied to recommend rehabilitation $[1,22]$ to the patients in the study, $>90 \%$ should have been included in a rehabilitation programme. Although the direct effect of respiratory rehabilitation on the use of the health services remains controversial, it has been found to be effective in reducing dyspnoea and improving the quality of life [9]. The low rate of rehabilitation is due to the lack of provision in the study hospitals during the recruitment year. Currently, only one of four hospitals is systematically offering a short programme of muscular training for COPD patients after the admission. In the current context of costcontainment, the lack of evidence with regards the effectiveness of rehabilitation, until recently [9], and the limited evidence on its cost-effectiveness for COPD patients [25], is in favour of the argument that rehabilitation programmes for COPD are not offered frequently enough.

The prevalence of current smoking was $26 \%$, slightly lower than the $33 \%$ [6] or $34 \%$ [26] reported by other studies on COPD patients hospitalized for exacerbation, but it is still a high proportion considering the consequences. Stopping smoking is the main treatment for COPD [1,22], and the patients that do not succeed will see their FEV1 decreasing at a faster rate [12]. In addition, it was found that $21 \%$ of noncurrent smokers were exposed to passive smoking at home, which is likely to be harmful, although the effect of passive smoking on patients suffering from COPD has not been assessed [13]. Overall, the authors found that little specific advice about methods for quitting active or avoiding passive smoking is given by the physician, something which must be addressed, considering that it is currently being recommended for all health

Table 2. - Prevalence of risk factors, by severity of the disease (American Thoracic Society classified stages), adjusted for sex, age, marital status and level of education

\begin{tabular}{|c|c|c|c|c|c|}
\hline & $\begin{array}{c}\text { Total } \\
(353 / 404)^{*}\end{array}$ & $\begin{array}{l}\text { FEV } 1 \geq 50 \% \\
\quad(41 / 42)\end{array}$ & $\begin{array}{c}\mathrm{FEV}_{1}=35-49 \% \\
(73 / 81)\end{array}$ & $\begin{array}{l}\text { FEV } 1<35 \\
(178 / 218)\end{array}$ & $\begin{array}{l}\text { Missing FEV1 } \\
(61 / 63)\end{array}$ \\
\hline No influenza vaccination & $28(24-33)$ & $28(16-43)$ & $26(17-36)$ & $29(23-35)$ & $28(18-40)$ \\
\hline No rehabilitation in the last year & $86(82-89)$ & $94(83-98)$ & $90(81-95)$ & $84(78-88)$ & $86(75-93)$ \\
\hline No LTOT when $\mathrm{PO}_{2} \leq 55 \mathrm{mmHg}$ & $28(20-39)$ & & $50(17-83)$ & $26(17-38)$ & \\
\hline LTOT $<15 \mathrm{~h} \cdot$ day $^{-1}$ & $18(13-25)$ & $34(11-67)$ & $23(9-48)$ & $13(8-21)$ & $35(17-60)$ \\
\hline Fail essential inhaler manoeuvres (MDI) & $43(38-48)$ & $48(30-66)$ & $36(25-48)$ & $43(36-50)$ & $47(33-61)$ \\
\hline Current smoking & $26(22-31)$ & $33(20-50)$ & $31(22-43)$ & $17(13-23)^{+}$ & $30(19-43)$ \\
\hline Passive smoking in noncurrent smokers ${ }^{\dagger}$ & $21(17-26)$ & $26(13-46)$ & $19(11-32)$ & $19(14-26)$ & $25(14-40)$ \\
\hline Current occupational pollution exposure & $5(3-8)$ & $2(0-12)$ & $1(0-4)$ & $0(0-2)$ & $1(0-6)$ \\
\hline
\end{tabular}

Data presented as prevalence $\left(95 \%\right.$ confidence interval). ${ }^{*}$ : Number of individuals/admissions; ${ }^{\dagger}: 90 \%$ of whom are exsmokers; ${ }^{+}$: $\mathrm{p}=0.004$ in comparison to the groups of moderate and mild disease; -: not possible to calculate due to small sample size; FEV1: forced expiratory volume in one second; LTOT: long-term oxygen therapy; MDI: metered dose inhalers. 
professionals to give advice on nicotine replacement therapy to all smokers at every opportunity [27].

The indications for LTOT for COPD patients are well established [1,22]. Patients who need LTOT but do not use it will have a poorer survival rate than those correctly treated $[10,11]$. In Catalunya, a great effort has been devoted to improve LTOT prescription [28], but yet a moderate rate of underprescription was found in this study (28\%), which shows that there is a need to improve hospital and outpatient management schemes. In the present sample, LTOT noncompliance was found to be $\sim 20 \%$, lower than the $44 \%$ [29] or $55 \%$ [30] reported by other studies that measured compliance from the concentrator counter. The most likely explanation for the difference is that self-reported habits in this study could result in an increased compliance rate being recorded.

Of the patients, $43 \%$ failed in some of the essential MDI manoeuvres, this was lower than the $76 \%$ found by VAN DER PALEN et al. [19] in COPD patients attending an outpatient department. Other studies found a high prevalence of noncompliance with MDI in COPD [31] or asthmatic [32] patients, and even in medical personnel [33]. This, together with the fact that a high proportion of the patients in the present study reported having been taught the inhaler manoeuvre (and rechecked), and that there are less mistakes made with dry powder devices than with MDI, could suggest that the problem is inherent to the MDI, rather than related to the patients or physicians. Other bronchodilator devices are more expensive, but their prescription should be considered if the correct deposition of the bronchodilator in the lungs is to be ensured.

Although current exposure to occupational pollution was low $(5 \%)$, partly due to the low numbers currently working ( $7 \%$ of total), whether the patients were taking protective measures in the workplace would need to be assessed, as per the ERS guidelines recommendations [1], and the measures of social protection available also need to be considered.

One of the limitations of the present study is that the inclusion of the various risk factors of COPD exacerbation was not based on a systematic critical appraisal of the literature. For this reason, a substantial part of the discussion provides a narrative review of the available literature. Although the authors see their approach as appropriate in the context of the current knowledge, it is clear that more research is needed concerning the nature and importance of the determinants of COPD exacerbations. The present study was hospital-based both because its feasibility and the economic importance of COPD admissions. However, its results should be interpreted with caution and not generalized to the whole COPD population. A risk factor of hospitalization in exacerbated COPD patients will always be more prevalent in a hospital based sample than in a community-based sample the difference between both prevalences being a function of the magnitude of the relative risk. Although further studies in community-based samples of COPD patients are needed, the results strongly suggest that COPD patients in general are not sufficiently well managed and that there is a large potential for improvement.

A degree of nonresponse (selection) bias is probably present, although the participation rate was $82 \%$, higher than in other studies on hospitalized COPD patients requested to answer a questionnaire [6, 34]. The lower prevalence of coexisting chronic conditions in nonresponders could be explained by the fact that there was no data in the medical record about the milder diseases that were asked about in the questionnaire (e.g. rheumatism or headaches). The higher prevalence of LTOT amongst the nonresponders may suggest that these patients have a more severe disease, although no differences in FEV1 were found. The authors opinion is that nonresponse has not led to a biased prevalence. The lack of lung function tests for some patients could be seen as a problem of misclassification, as some non-COPD subjects could have been included. However, only $5.5 \%$ of all episodes with spirometry performed were excluded due to either a FEV $1 /$ FVC ratio $>88 \%$ or a positive bronchodilator test. If this $5.5 \%$ level was applied to episodes without spirometric values $(n=62)$, only three of them would have been excluded. Moreover, the comparison between patients with performed tests and those without, only showed differences in the proportion of comorbidities, and no other differences were found in sociodemographic or clinical variables or in the prevalence of risk factors. In the authors view, if there is some misclassification, it has very little impact on the prevalence rates.

It may be argued that the present results are merely a reflection of local practices and therefore, cannot be generalized. However, as shown in the discussion, a moderate to high prevalence for most of the risk factors considered has been observed in many different areas. Even if some of the observed results are only local, the description and understanding of local variations in other fields of healthcare have proved to be a very successful research approach [35].

To conclude, a moderate to high prevalence of potentially modifiable risk factors in a large representative sample of patients hospitalized for a COPD exacerbation was found, suggesting unsatisfactory features in their management. For those factors with well established relevance in chronic obstructive pulmonary disease exacerbation, more effort in monitoring and improving patterns of care is needed. For some of the factors suspected to be relevant for chronic obstructive pulmonary disease exacerbation, the high prevalence rates reported in the study reveal the need to investigate their true impact on its exacerbation.

EFRAM investigators. J. Alonso, J.M. Antó (Principal Investigator), J. Garcia-Aymerich and J. Sunyer (Respiratory and Environmental Health Research Unit, IMIM, Barcelona); E. Barreiro and M.A. Félez (Dept of Pneumology, Hospital del Mar, Barcelona); J. Escarrabill, E. Farrero and M.J. Redondo (Dept of Pneumology, Ciutat Sanitària i Universitària de Bellvitge, L'Hospitalet de Llobregat); R.M. Marrades, N. Soler and A. Torres (Dept of Pneumology, Hospital Clínic i Provincial de Barcelona, Barcelona); G. Bonel, J. Izquierdo, E. Monsœ and J. Morera (Dept of Pneumology, Hospital Germans Trias i Pujol, Badalona).

Acknowledgements. The authors would like to thank M. Macharé, M. Maresma, A. Martń, M.J. Rodrǵuez, S. Alonso, R. Reinón, R. Pedreny, N. Soler and A. Roig for their help in the fieldwork, and X. Basagaña for his statistical counselling. 


\section{References}

1. Siafakas NM, Vermeire $\mathrm{P}$, Pride NB, et al. Optimal assessment and management of chronic obstructive pulmonary disease (COPD). Eur Respir $J$ 1995; 8: 1398-1420.

2. Connors AF, Dawson NV, Thomas C, et al. Outcomes following acute exacerbation of severe chronic obstructive lung disease. Am J Respir Crit Care Med 1996; 154: 959-967.

3. Seemungal TAR, Donaldson GC, Paul EA, Bestall JC, Jeffries DJ, Wedzicha JA. Effect of exacerbation on quality of life in patients with chronic obstructive pulmonary disease. Am J Respir Crit Care Med 1998; 157 : $1418-1422$.

4. Fagon JY, Chastre J. Severe exacerbations of COPD patients: the role of pulmonary infections. Semin Respir Infect 1996; 11: 109-118.

5. Madison JM, Irwin RS. Chronic obstructive pulmonary disease. Lancet 1998; 352: 467-473.

6. Poole PJ, Bagg B, Brodie SM, Black PN. Characteristics of patients admitted to hospital with chronic obstructive pulmonary disease. $N Z$ Med $J$ 1997; 110: 272-275.

7. Nichol KL, Baken L, Nelson A. Relation between influenza vaccination and outpatient visits, hospitalisation, and mortality in elderly persons with chronic lung disease. Ann Intern Med 1999; 130: 397-403.

8. Anderson HR, Spix C, Medina S, et al. Air pollution and daily admissions for chronic obstructive pulmonary disease in 6 European cities: results from the APHEA project. Eur Respir J 1997; 10: 1064-1071.

9. Lacasse Y, Wong E, Guyatt GH, King D, Cook DJ, Goldstein RS. Meta-analysis of respiratory rehabilitation in chronic obstructive pulmonary disease. Lancet 1996; 348: 1115-1119.

10. Medical Research Council. Long term domiciliary oxygen therapy in chronic hypoxic cor pulmonale complicating chronic bronchitis and emphysema. Lancet 1981; 1: 681-686.

11. Noctumal Oxygen Therapy Group. Continuous or nocturnal oxygen therapy in hypoxaemic chronic obstructive lung disease. A clinical trial. Ann Intern Med 1980; 93: 391-398.

12. Fletcher CM, Peto R, Tinker C. The natural history of chronic bronchitis and emphysema. Oxford University Press, New York, 1996.

13. Coultas DB. Passive smoking and risk of adult asthma and COPD: and update. Thorax 1998; 53: 381-387.

14. Becklake MR. Occupational exposures: evidence for a causal association with chronic obstructive pulmonary disease. Am Rev Respir Dis 1989; 140: S85-S91.

15. Alonso J, Antó JM. Enquesta de Salut de Barcelona 1986. Ajuntament de Barcelona. Barcelona, 1989.

16. Alvarez-Dardet C, Alonso J, Domingo A, Regidor E. La medición de la clase social en Ciencias de la Salud. SG Editores, Barcelona, 1995.

17. Borg GAV. Psychophysical bases of perceived exertion. Med Sci Sports Exerc 1982; 14: 377-381.

18. Burney PGJ, Luczynska C, Chinn S, Jarvis D. The European Community Respiratory Health Survey. Eur Respir J 1994; 7: 954-960.
19. Van der Palen J, Klein JJ, Kerkhoff AHM, Van Herwaarden CLA. Evaluation of the effectiveness of four different inhalers in patients with chronic obstructive pulmonary disease. Thorax 1995; 50: 1183-1187.

20. Grupo de trabajo de la SEPAR para la práctica de la espirometra en clíica. Normativa para la espirometrúa forzada. Ed. Doyma, Barcelona, 1985.

21. Roca J, Sanchis J, Agusti-Vidal A, et al. Spirometric reference values from a Mediterranean population. Bull Eur Physiopathol Respir 1986; 22: 217-224.

22. American Thoracic Society. Standards for the diagnosis and care of patients with chronic obstructive pulmonary disease. Am J Respir Crit Care Med 1995; 152: S77S120.

23. Diggle P, Liang K, Zeger SL. Analysis of longitudinal data. New York, Oxford Science Publications, 1994; pp. 143-145.

24. Büchi S, Villiger B, Sensky T, Schwars F, Wolf C, Buddeberg C. Psychosocial predictors of long-term success of in-patient pulmonary rehabilitation of patients with COPD. Eur Respir J 1997; 10: 1272-1277.

25. Goldstein RS, Gort EH, Guyatt GH, Feeny D. Economic analysis of respiratory rehabilitation. Chest 1997; 112: 370-379.

26. Kessler R, Faller M, Fourgaut G, Mennecier B, Weitzenblum E. Predictive factors of hospitalization for acute exacerbation in a series of 64 patients with chronic obstructive pulmonary disease. Am J Respir Crit Care Med 1999; 159: 158-164.

27. Raw M, McNeill A, West R. Smoking cessation guidelines for health professionals. A guide to effective smoking cessation interventions for the health care system. Thorax 1998; 53: S1-S19.

28. Granados A, Escarrabill J, Borràs JM, Sánchez V, Jovell AJ. Utilización apropiada y efectividad: la oxigenoterapia cronica domiciliaria en Cataluna. Med Clin (Barc) 1996; 106: 251-253.

29. Morrison D, Skwarski K, MacNee W. Review of the prescription of domiciliary long-term oxygen therapy in Scotland. Thorax 1995; 50: 1103-1105.

30. Pépin JL, Barjhoux CE, Deschaux C, Brambilla C, ANTADIR. Long-term oxygen therapy at home. Compliance with medical prescription and effective use of therapy. Chest 1996; 109: 1144-1150.

31. Corden ZM, Bosley CM, Rees PJ, Cochrane GM. Home nebulized therapy for patients with COPD: patient compliance with treatment and its relation to quality of life. Chest 1997; 112: 1278-1282.

32. Larsen JS, Hahn M, Ekholm B, Wick KA. Evaluation of conventional press-and-breathe metered-dose inhaler technique in 501 patients. J Asthma 1994; 31: 193-199.

33. Hanania NA, Wittman R, Kesten S, Chapman KR. Medical personnel's knowledge of and ability to use inhaling devices. Chest 1994; 105-116.

34. Osman LM, Godden DJ, Friend JAR, Legge JS, Douglas JG. Quality of life and hospital re-admission in patients with chronic obstructive pulmonary disease. Thorax 1997; 52: 67-71.

35. Wennberg J, Gittelsohn A. Small area variations in health care delivery. Science 1973; 182: 1102-1108. 